\title{
IoT based temperature and humidity monitoring framework
}

\author{
Rafizah Ab Rahman', Ummi Raba'ah Hashim², Sabrina Ahmad ${ }^{3}$ \\ ${ }^{1}$ Department of Information Technology and Communication, Politeknik Muadzam Shah, Pahang, Malaysia \\ ${ }^{2,3}$ Centre for Advanced Computing Technology, Fakulti Teknologi Maklumat dan Komunikai, Universiti Teknikal \\ Malaysia Melaka (UTeM), Melaka, Malaysia
}

\begin{tabular}{|c|c|}
\hline Article Info & ABSTRACT \\
\hline Article history: & \multirow{9}{*}{$\begin{array}{l}\text { This study explored the use of Internet of Things (IoT) in monitoring } \\
\text { the temperature and humidity of a data centre in real-time using a simple } \\
\text { monitoring system to determine the relationship and difference between } \\
\text { temperature and humidity with respect to the different locations } \\
\text { of measurements. The development of temperature and humidity monitoring } \\
\text { system was accomplished using the proposed framework and has been } \\
\text { deployed at the data centre of Politeknik Muadzam Shah, where the readings } \\
\text { were recorded and sent to an IoT platform of AT\&T M2X to be stored. } \\
\text { The data was then retrieved and analysed showing that there was } \\
\text { a significant difference in temperature and humidity measured at different } \\
\text { locations. X The monitoring system was also successful in detecting extreme } \\
\text { changes in temperature and humidity and automatically send a notification to } \\
\text { IT personnel via e-mail, short messaging service (SMS) and mobile push } \\
\text { notification for further action. }\end{array}$} \\
\hline Received Feb 27, 2019 & \\
\hline Revised May 22, 2019 & \\
\hline Accepted Jul 24, 2019 & \\
\hline Keywords: & \\
\hline Arduino & \\
\hline AT\&T M2X & \\
\hline Internt of Things (IoT) & \\
\hline $\begin{array}{l}\text { Temperature and humidity } \\
\text { monitoring }\end{array}$ & \\
\hline
\end{tabular}

This is an open access article under the $\mathrm{CC}$ BY-SA license.

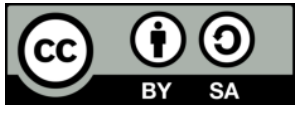

\section{Corresponding Author:}

Rafizah Ab Rahman,

Faculty of Information Technology and Communication,

Politeknik Muadzam Shah,

Lebuhraya Tun Razak, 26700 Muadzam Shah, Pahang, Malaysia.

Email: rafizah@pms.edu.my

\section{INTRODUCTION}

IoT Cloud-based Framework has been proposed and discussed to be used in many domains ranging from health, agriculture, environmental monitoring, to remote automation in various industries [1] had designed a real-time remote monitoring with data acquisition system consists of a DHT11 temperature sensor, Atmel Atmega 2560 microprocessor, and GSM/GPRS that were connected to the web server. However, [2-3] only developed the system to evaluate the workability of the device and no further analysis was conducted towards data collected.

IoT Cloud-based Framework has gained popularity in the agriculture domain by facilitating the monitoring of farmland using low-cost devices that can cover a vast amount of area using either GSM/GPRS, ZigBee, or MQTT [4-6]. Another domain where IoT Cloud-based Framework was used is the data centre temperature monitoring [7-9]. However, only [3, 5, 6] used Platform-as-a-Service (PaaS) IoT platform, such as AT\&T M2X and Losant, to store and analysed their data while the others developed their own data server to store their data. ZigBee protocol is widely used in various studies as it is proven to be efficient, lightweight, and require a low power source [4, 7, 9-11].

To meet the low-cost development requirement, $[1,7,9,11]$, used the microcontroller Arduino Board range using either Ethernet, ZigBee, or GSM/GPRS shield to connect to the internet. However, Texas Instrument TI CC3200 LaunchPad Board and TI CC2530 board used SimpleLink Wi-Fi module and RF Solution-on-Chip, respectively, integrating on the board for connectivity making it ideal to be 
used mostly indoors $[3,6]$. Another board of choice is NodeMCU, an open source IoT platform running on ESP8266 Wi-Fi SoC with full TCP/IP stack [12-13].

Temperature monitoring in agriculture by [4] employed the use of SHT15 sensor by Sensirion, which is capable of measuring temperature in the range of $-40^{\circ} \mathrm{C}$ to $123.8^{\circ} \mathrm{C}$. In the same family, the SHT11 temperature sensor was also used $[2,11]$ where the measurement of humidity is calculated based on the measurement of the temperature. [10] used fibre optic sensor to measure the temperature of the liquefied petroleum storage tank due to its insusceptibility to electromagnetic interference and the material of glass structure of what it made of, making it resistant to a very high temperature. $[3,7]$ used integrated sensor HRT393 and LM335A, respectively, to measure both the relative humidity and the temperature using formulas based on the analogue voltage output of HRT393 and Arduino. Meanwhile, [11] used a variety of temperature and humidity sensors such as DHT11, Grove Temp, BMP085, and DS18B20 to compare the readings measured by different sensors.

The modern data centre has faced challenges in the era of big data where billions of devices are connected to the internet and each other, placing an ever-increasing pressure on the IT departments with the demands for data management that can be instanta neously a vailable to end users. Emphasising on en ergy efficiency improvement and cooling innovation aims to reduce the cost of operation. Since the data centre components mainly consist of electrical and mechanical parts, an exposure to a continuous high tempera ture may cause failures [14]. A proper room layout design in a data centre with an optimal cooling solution is essential in ensuring optimum operating condition. However, some organisations overlooked this important a spect and need to face the prohibitive cost to revamp the room layout. Scenarios where IT personnel walked in on Monday morning after the weekend into the data centre, discovering that the air conditioning was off due to power outage or malfunction, can be avoided by implementing temperature monitoring system that is also suggested by [15] to prevent server shutdown due to overheating.

The temperature monitoring in the data centre is very crucial as overheated equipment will result in shorter lifespan leading to unexpected failure in the future, even when the air conditioning is well-functioning. Moreover, humidity, relative to the temperature, will increase if the temperature is too cold causing corrosion on the equipment or condensation that can damage the equipment. Inversely, if the temperature is too high, decreasing the humidity leads to static build-up that can also damage the equipment. One of the method used previously to prevent server overheating is by cooling the data centre extensively [15]. However, this method will lead to an excessive use of power, consequently, increase the energy consumption of the data centre.

A monitoring system is able to ensure the temperature range of the server inlet is maintained at $18-27^{\circ} \mathrm{C}[16]$. However, providing human resources for monitoring the temperature and humidity of the data centre at all times is impractical and may increase the cost incurred for the human resources. Periodic monitoring by IT personnel which is commonly practised requires a frequent physical access into the data centre, which may increase the possibilities of threats such as static build up, theft, sabotage of equipment, and unauthorised access. Without the automatic monitoring, IT personnel might not aware of any temperature spikes in the data centre especially over the weekend or long holiday. The real-time monitoring system available in the market today is very expensive, and even if it is affordable, it comes with limited functionality. Most systems are proprietary to the vendor, with a dditional costs for additional services such as warning a lerts, notifications, and extra sensors.

This study aims to design a real-time temperature and humidity monitoring that can be designed and deployed rapidly with the use of IoT Cloud platform. This study was conducted in the data centre of Politeknik Muadzam Shah, where two temperature and humidity sensors are placed at the outlet of two racks to measure the temperature and humidity of the rack and one sensor is placed outside of the rack to measure the room ambient temperature and humidity. This study also describes the distribution of temperature and humidity in a data centre. The relationship between temperature and humidity at three separate locations was determined and the significant difference on the measurement at these locations was investigated.

\section{RESEARCH METHOD}

The IoT based Temperature and Humidity Monitoring Framework proposed for this project that consists of sensor node hardware using Arduino Mega 2560 R3, Arduino-compatible ethernet shield, and DHT11 temperature and humidity sensors. The firmware that was developed using Arduino Integrated Development Environment (IDE) will send the data to AT\&T M2X IoT platform by utilising the RESTful API. The M2X platform has a trigger function feature, enabling an integration to the IFTTT service using RESTful API to push mobile and e-mail notification to users. 


\subsection{Sensor node hardware}

In various IoT based projects, most researchers designed their sensor nodes that consists of the popular open hardware solution from Arduino platform with compatible sensors [17-19]. The Ardu ino Mega 2560 R3 was chosen in this study as it can support the firmware and libraries for microSD, ethernet shield, OLED display and M2X with its $128 \mathrm{~KB}$ flash memory compared to Arduino UNO that has only $32 \mathrm{~KB}$. In addition, the large number of input/output pins a vailable allows the possibility and scalability of connecting various sensor modules in the future. The sensor used specifically for this study is the DHT11 temperature and humidity sensor capable of producing a calibrated digital signal as an output that ensures high reliability and long-term stability. Figure 1 shows the sensor node hardware setup developed and deployed for this study.
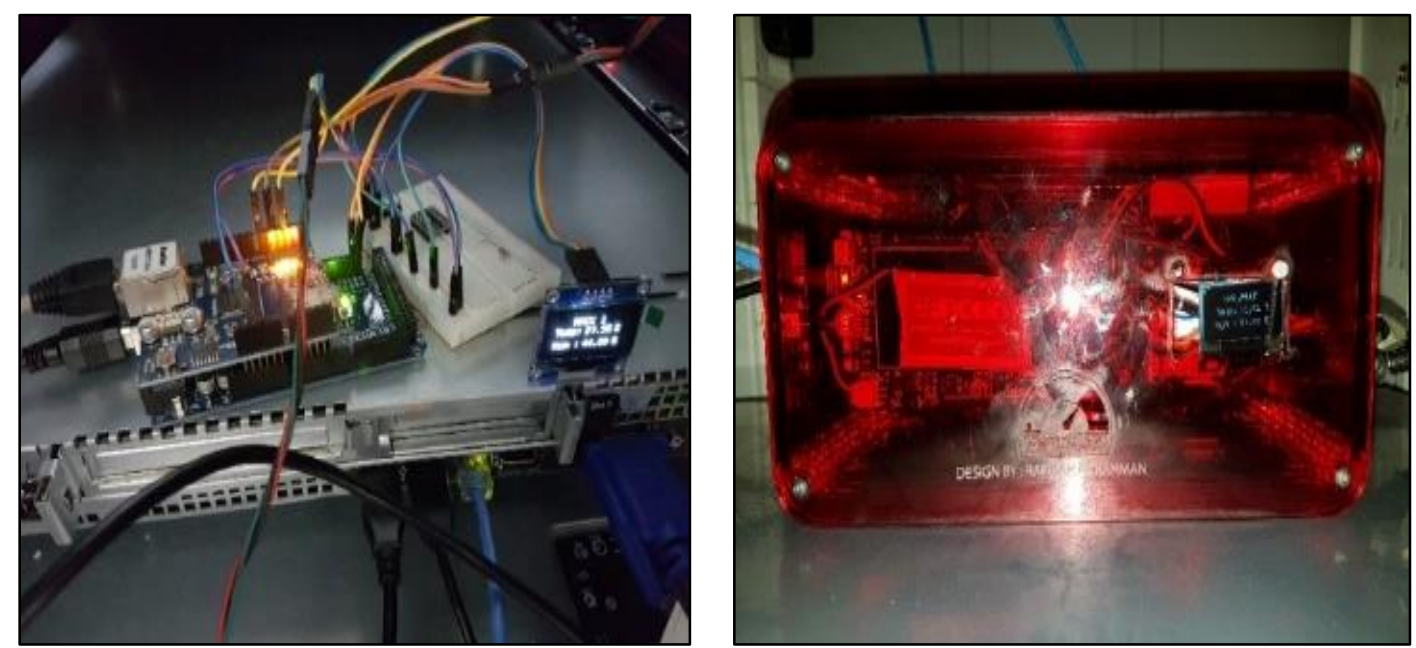

Figure 1. Photograph of sensor node hardware development

\subsection{AT\&T M2X IoT platform}

There are various IoT platforms available in the market today, each has their own set of generic features and capabilities that can be used to build IoT applications. IoT devices communicated with other IoT devices to generate a massive a mount of data and turned into a useful information using cloud connectivity, allowing users to implement business use cases, predictive maintenance, and analytics and real-time data management. IoT platforms are mostly cloud-based PaaS communicating with devices via internet, satellite, cellular, or Wi-Fi with persistent and dependable connectivity a s crucial factor [20].

M2X Time Series Data Storage is a cloud-based service offered by AT\&T to collect the real-time data from the sensors or connected devices and translate them into meaningful information. Each sensor connected to the device is identified by their device ID, API key, and stream name [3]. Tools provided by AT\&T M2X allows the developers to manage their devices and notifications from a central location, called the M2X Developer Portal. AT\&T M2X provides a growing list of client libraries for both hardware and software such as NET, Node.js, C, Elixir, Java, NODE-Red, PHP, Python, Ruby, Intel Galileo, Arduino, BeagleBone, Raspberry Pi, Android, and iOS. M2X's RESTful API ease the connection between devices and the M2X service allows the user to build IoT solutions without managing their own storage infrastructure.

\subsection{If this then that}

If This Then That (IFTTT) application offers an Interoperability-as-a-Service, allowing rapid integration with different services responding to events or triggers using applets customised by users [20-21]. IFTTT cuts down the complexities of connecting IoT data. For example, when an IoT device which is connected to AT\&T M2X sends a data exceeding a threshold value, M2X will trigger an action to IFTTT via a callback URL, instructing them to send a notification via SMS, e-mail or mobile notification to the recipients configured in the applet illustrated in Figure 2(a) to (d). 


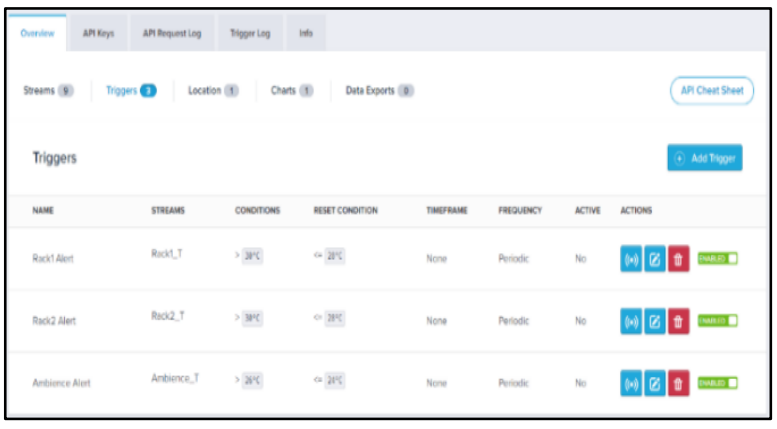

(a)

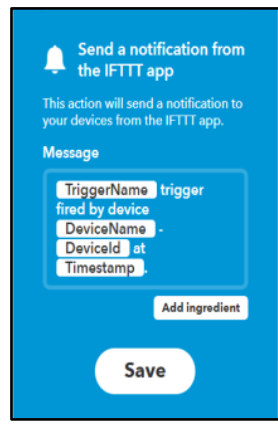

(b)

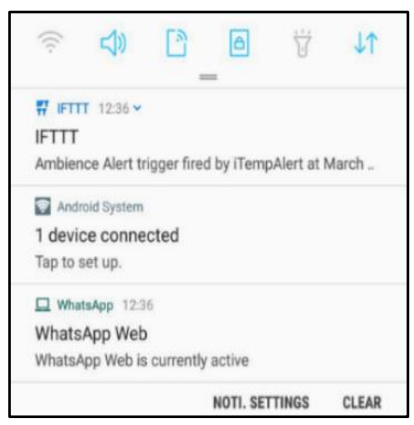

(c)

Figure 2. IFTTT integration, (a) M2X trigger function, (b) IFTTT applet setting,

(c) Mobile push notification by IFTTT

\section{RESULTS AND DISCUSSION}

Three sensors modules were installed in the data centre of Politeknik Muadzam Shah. Readings from the sensors were sent to the IoT platform via RESTful API, to be recorded. Figure 3 shows the data successfully recorded to the M2X platform. Each data stream is displayed in a real-time chart. The temperature and humidity readings were taken at three separate locations. The Ambient sensor was placed on top of the server rack, while Rack 1 and Rack 2 sensors were placed at the outlet of each rack. The data $\log$ for each stream can be downloaded in a .csv format for further a nalysis.

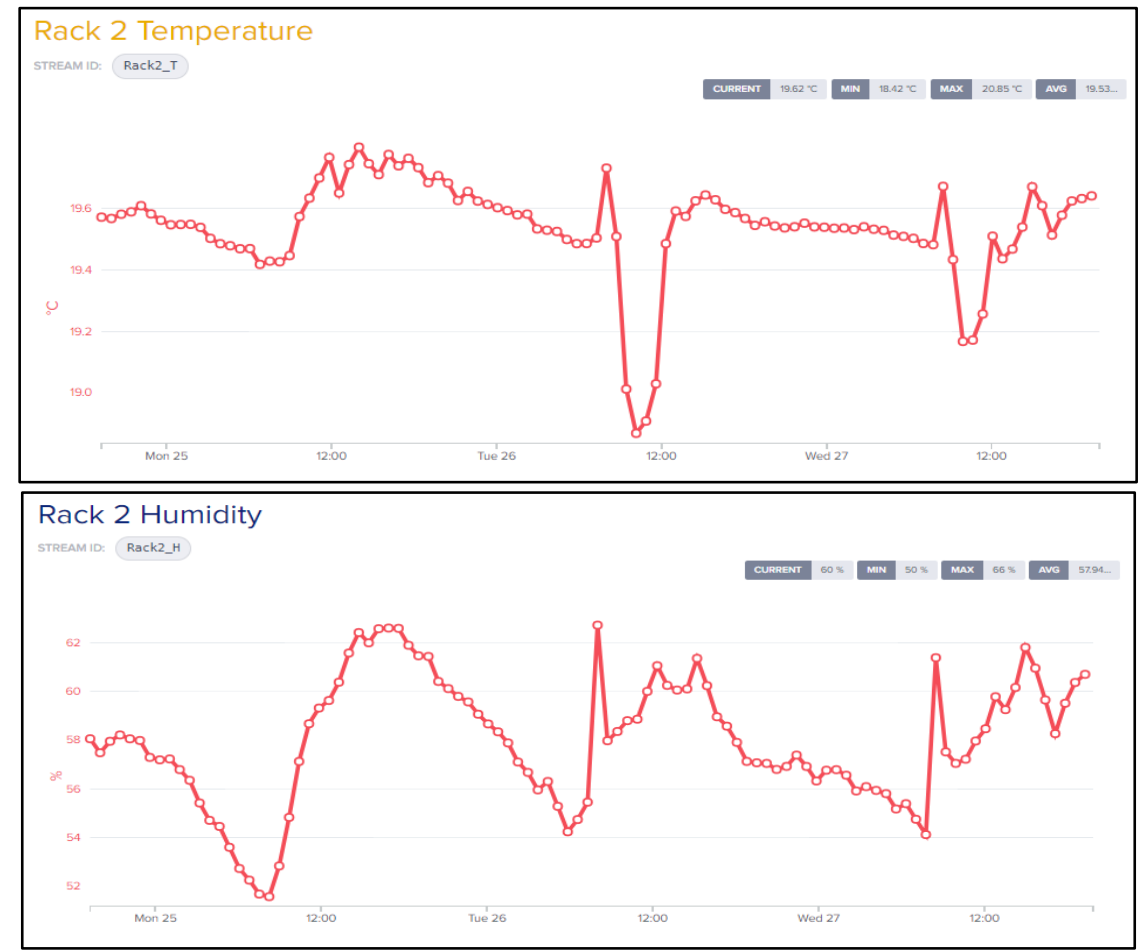

Figure 3. Screenshot of temperature and humidity data on AT\&T M2X platform

Upon investigation, humidity at all three locations recorded an obvious variation as opposed to the temperature that recorded miniscule fluctuation. This is probably contributed by the use of comfort cooling system in Politeknik Muadzam Shah data centre as depicted in Figure 4. The use of this system is known to contribute to the difficulty in maintaining stable dew point levels over extended periods due to the lack of built-in humidity control [22]. 


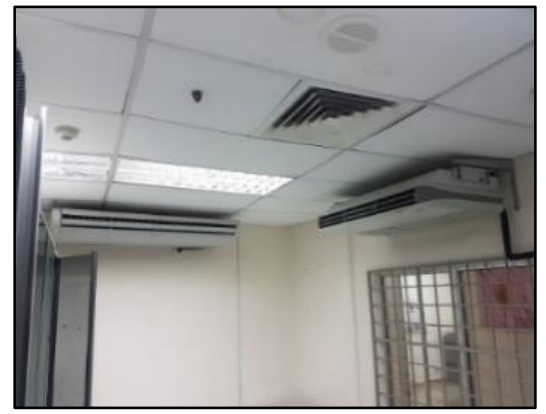

Figure 4. Comfort cooling system in Politeknik Muadzam Shah data centre

Figure 5 and Figure 6 shows the readings recorded for temperature and humidity for 3 locations within 10 days. Rack 1 recorded higher temperature data than Rack 2 and Ambient throughout the entire period as it contains several intensive heat-emitting equipment such as servers and disk storage compared to Rack 2 that only contains switches. However, the readings recorded indicates that the Rack 2 sensor has recorded a much higher humidity than Ambient and Rack 1. Further investigation rev eals that Rack 2 uses glass front door and closed-cabinet type of rear door rather than the vented door used for Rack 1 as shown in Figure 7(a) and (b). Higher humidity in Rack 2 may be attributed to the use of these doors as described in a previous study [23]. These doors are classified as a design flaw of racks, contributing to the overheating problem as it obstructs air circulation through the rack inlet, suggesting the use of the fully vented door to promote better airflow.

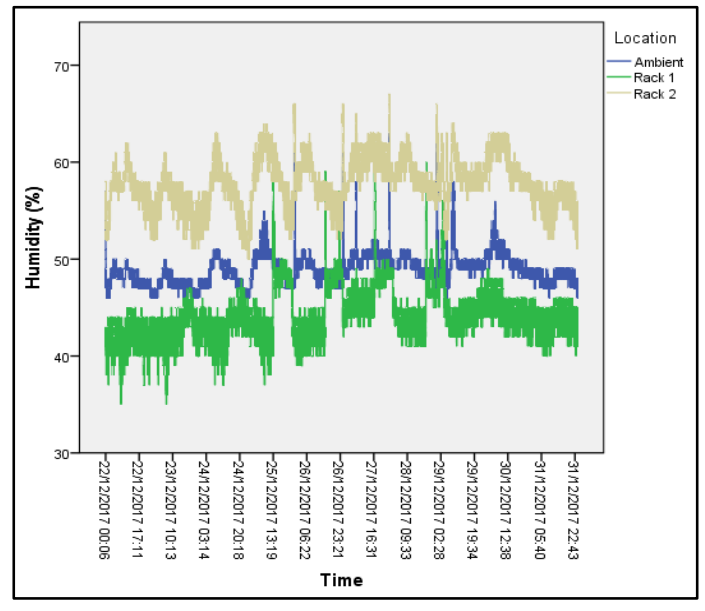

Figure 5. Humidity readings

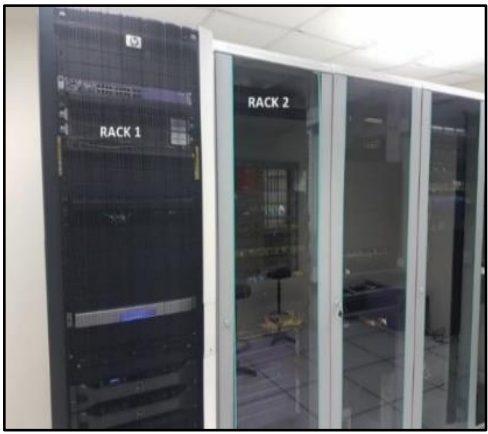

(a)

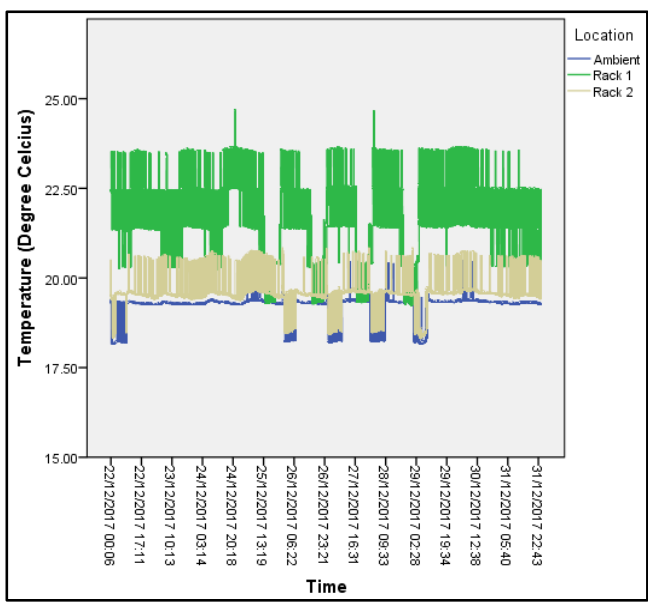

Figure 6. Temperature readings

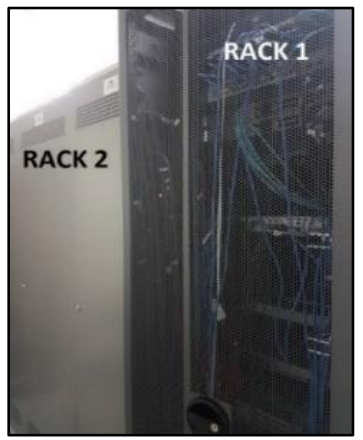

(b)

Figure 7. (a) Racks' rear door, (b) Racks's front door 
Descriptive statistic evaluates the sensor data collected by a real-time monitoring system using AT\&T M2X IoT platform. The data was then retrieved from the AT\&T M2X server and exported to a spreadsheet program before being copied to SPSS program. Two variables data for the humidity and temperature were analysed. As the data for both variables are interval-scaled, descriptive mea sures of centra 1 tendency were used. The descriptive measures of central tendency were described by the mode, median, and mean denoting the central position of the data collected.

The measures of central tendency were computed to summarise the data for the temperature and humidity variables. The mean for Ambient humidity recorded was 48.93, with 1.62 s.d and the mea n for Ambient temperature recorded was 19.22 with 0.34 s.d. On the other hand, Rack 1 humidity recorded the mean value of 44.21 with 2.5 s.d, and mean temperature of 21.9 with 0.97 s.d. Likewise, Rack 2 humidity recorded the mean value of 57.8 with 2.55 s.d and mean temperature of 19.53 with 0.26 s.d. Rack 1 recorded the highest mean temperature among all three locations with the lowest humidity. This is probably contributed by the fact that it contains several intensive heat-emitting equipment such as servers, in contrast to Rack 2 that only contains switches. The difference between the mean and the median is not significant with a small value of standard deviation, concluding that the mean can be the indicator of average temperature and humidity.

Descriptive statistic evaluates the sensor data collected by a real-time monitoring system using AT\&T M2X IoT platform. The data was then retrieved from the AT\&T M2X server and exported to a spreadsheet program before being copied to SPSS program. Two variables data for the humidity and temperature were analysed. As the data for both variables are interval-scaled, descriptive measures of central tendency were used. The descriptive measures of central tendency were described by the mode, median, and mean denoting the central position of the data collected.

The measures of central tendency were computed to summarise the data for the temperature and humidity variables. Table 1 detailed out the analysis of temperature and humidity for each location. The mean for Ambient humidity recorded was 48.93, with 1.62 s.d and the mean for Ambient temperature recorded was 19.22 with 0.34 s.d. On the other hand, Rack 1 humidity recorded the mean value of 44.21 with 2.5 s.d, and mean temperature of 21.9 with 0.97 s.d. Likewise, Rack 2 humidity recorded the mean value of 57.8 with 2.55 s.d and mean temperature of 19.53 with 0.26 s.d. Rack 1 recorded the highest mean temperature among all three locations with the lowest humidity. This is probably contributed by the fact th at it contains several intensive heat-emitting equipment such as servers, in contra st to Rack 2 that only conta in s switches. The difference between the mean and the median is not significant with a small value of standard deviation, concluding that the mea n can be the indicator of a vera ge temperature and humidity.

\begin{tabular}{|c|c|c|c|}
\hline & Location & Humidity & Temperature \\
\hline \multirow{4}{*}{ Ambien } & Mean & 48.93 & 19.2207 \\
\hline & $\mathrm{N}$ & 29227 & 29227 \\
\hline & ${ }^{\mathrm{n}}$ Std. Deviation & 1.616 & .33759 \\
\hline & Median & 49.00 & 19.3300 \\
\hline \multirow{4}{*}{ Rack 1} & Mean & 44.21 & 21.8961 \\
\hline & $\mathrm{N}$ & 29227 & 29227 \\
\hline & Std. Deviation & 2.496 & .96851 \\
\hline & Median & 44.00 & 22.4300 \\
\hline & Mean & 57.98 & 19.5374 \\
\hline & $\mathrm{N}$ & 29227 & 29227 \\
\hline & Std. Deviation & 2.550 & .26029 \\
\hline & Median & 58.00 & 19.5700 \\
\hline \multirow{4}{*}{ Total } & Mean & 50.37 & 20.2181 \\
\hline & $\mathrm{N}$ & 87681 & 87681 \\
\hline & Std. Deviation & 6.147 & 1.34084 \\
\hline & Median & 49.00 & 19.5700 \\
\hline
\end{tabular}

A one-way analysis of variance was conducted to explore the impact of location on humidity and temperature. Three locations were selected to measure the humidity and temperature data, namely Ambient, Rack 1, and Rack 2. Table 2 shows the results indicating that there was a significant difference at $\mathrm{p}<0.05$ level for all three locations in the temperature $[\mathrm{F}(2,87678)=167331.5, \mathrm{p}<0.05]$ and humidity $[\mathrm{F}(2,87678)=279973.73, \mathrm{p}<0.05]$ recorded. The actual difference in the mean scores for the temperatures recorded between the Ambient and Rack 2 was quite small. The results from Table 2 are used to de termine the eta squared value, which recorded a very large effect on both humidity (0.87) and temperature $(0.79)$. 
Post-hoc comparison using the Scheffe test indicating that the mean humidity recorded for Ambient was 48.93 with s.d of 1.61. A significant difference was recorded for Rack 1 with mean humidity of 44.21 and s.d of 2.5, as well as for Rack 2 with mean humidity of 57.98 and s.d of 2.55, compared to the Ambient. The values of mean humidity and s.d for both Rack 1 and Rack 2 also shows a significant difference with one another. Meanwhile the mean temperature recorded for Ambient is 19.22 with s.d of 0.38. A significant difference was recorded for Rack 1 with mean=21.9 and, s.d=0.97 and Rack 2 with mean=19.54 and s.d=0.26 compared to Ambient, while the mean temperatures of both Rack 1 and Rack 2 also shows significant difference with one another.

Table 2. Anova

\begin{tabular}{|c|c|c|c|c|c|c|}
\hline & & Sum of Squares & $\mathrm{df}$ & Mean Square & $\mathrm{F}$ & Sig. \\
\hline \multirow{3}{*}{ Humidity } & Between Groups & 2864174.263 & 2 & 1432087.132 & 279973.726 & .000 \\
\hline & Within Groups & 448479.710 & 87678 & 5.115 & & \\
\hline & Total & 3312653.973 & 87680 & & & \\
\hline \multirow{3}{*}{ Temperature } & Between Groups & 124909.992 & 2 & 62454.996 & 167331.497 & .000 \\
\hline & Within Groups & 32725.035 & 87678 & .373 & & \\
\hline & Total & 157635.027 & 87680 & & & \\
\hline
\end{tabular}

A Pearson product-moment correlation coefficient was computed to assess the relationship between the humidity, the temperature, and the location in a data centre. With regards to humidity and temperature, Table 3 indicates that there was a large negative correlation between the two variables, where $r=-0.605, n=87681, p<0.05$. According to guidelines by Evans, 2016 cited in [24], the $r$ value shows a strong negative relationship between the humidity and temperature. The increase in temperature correlates to the decrease in humidity. Furthermore, the relationship between the location and the temperature shows a very small positive correlation, significantly at the 0.01 level between the two variables, $r=0.096, n=87681$, $\mathrm{p}<0.05$, concluding a very weak relationship. A large positive correlation was also reflected in the relationship between the humidity and the location where $r=0.61, n=87681, p<0.05$ indicating a strong positive significant relationship. Overall, this shows that different locations had a slightly significant relationship on temperature with only $0.92 \%$ of shared variance recorded but had a significant relationship on humidity with $36.12 \%$ of shared variance recorded.

Table 3. Pearson correlations

\begin{tabular}{|c|c|c|c|c|}
\hline & & Location & Humidity & Temperature \\
\hline \multirow{3}{*}{ Location } & Pearson Correlation & 1 & .601 & .096 \\
\hline & Sig. (2-tailed) & & .000 & .000 \\
\hline & $\mathrm{N}$ & 87681 & 87681 & 87681 \\
\hline \multirow{3}{*}{ Humidity } & Pearson Correlation & $.601^{* *}$ & 1 & $-.605^{* *}$ \\
\hline & Sig. (2-tailed) & .000 & & .000 \\
\hline & $\mathrm{N}$ & 87681 & 87681 & 87681 \\
\hline \multirow{3}{*}{ Temperature } & Pearson Correlation & $.096^{* *}$ & $-.605^{* *}$ & 1 \\
\hline & Sig. (2-tailed) & .000 & .000 & \\
\hline & $\mathrm{N}$ & 87681 & 87681 & 87681 \\
\hline
\end{tabular}

**. Correlation is significant at the 0.01 level (2-tailed)

To sum it up, the analysis reveals that the humidity for each location, namely the Ambient, Rack 1 , and Rack 2, varied greatly with the mean difference between Ambient and Rack 1 (4.721), Ambient and Rack 2 (9.054), and Rack 1 and Rack 2 (13.774). On the other hand, the mean difference of temperature recorded between the Rack 1 and Rack 2 was 2.36 and the mean difference of temperature recorded between the Ambient and Rack 2 was 0.32 . A much higher mean difference of temperature was recorded between Ambient and Rack 1 which was 2.36. The maximum temperature of the data centre slightly fluctuates from $18.16{ }^{\circ} \mathrm{C}$ to $24.7{ }^{\circ} \mathrm{C}$, while the humidity varied from $35 \%$ to $67 \%$. A similar temperature and humidity trends were also depicted in a study by [9]. From the analysis, it can be concluded that:

- there is a significant difference between temperature and humidity at different locations.

- there is a strong significant relationship between temperature and humidity.

The analysis also indicates that, compared to the temperature difference between the minim um and maximum value of $36 \%$, humidity recorded a much larger difference of $91 \%$. On further investiga tion, it wa s discovered that the layout of the data centre in Politeknik Muadzam Shah was poorly designed where it comprises of three units of comfort air-conditioning operating for 24 hours, utilising two units at a time in addition to a centralised air-conditioning that only operated during working hours of 8.00 a.m. to 5.00 p.m. 
The comfort cooling systems were not designed to regulate the humidity and the temperature within a precise margin [22], making it harder to maintain the stable dew point levels over extended periods. Moreover, the lack of cold aisle and hot aisle containment to prevent the re-circulation of hot air from the heat-generating components to computer room air-conditioning (CRAC) air [25-27] were not implemented.

\section{CONCLUSION}

In this study, the design and the implementation of the temperature and humidity monitoring system were discussed to obtain a better perspective on the temperature and humidity distribution of a data centre located in Politeknik Muadzam Shah. The use of Internet of Things (IoT) platform such as AT\&T M2X has greatly reduced the hassle of setting up a complex storage to record and analyse the data of temperature and humidity. The practice of using only a room thermometer to monitor the environment of a small data centre is not enough as several studies including this study have proven that the temperature and humidity differ significantly in different locations. Understanding the data on the temperature and humidity distribution is a first step towards improving the monitoring system of a data centre. Deployment pattern of sens or modules needs to be considered in the future to obtain a much well-rounded data. Further development of the monitoring system can include the addition of control mechanism that responds to any changes to the temperature and humidity to truly automate the existing process. Additional sensors such as airflow sensor, pressure sensor, and the current sensor, can be used to widen the scope of the study, to explore the development of temperature and humidity prediction model, and enhancing the environmenta 1 monitoring and control of a data centre.

\section{ACKNOWLEDGEMENTS}

This research is supported by Politeknik Muadzam Shah and Universiti Teknikal Malaysia Melaka (UTeM) under UTeM Short Term Research Grant (PJP/2018/FTMK(3B)/S01630).

\section{REFERENCES}

[1] A. F. Z. Abidin, M. H. Jusoh, E. James, S. A. M. Al Junid, and A. I. M. Yassin, "Real-time remote monitoring with data acquisition system," in IOP Conference Series: Materials Science and Engineering, vol. 99, no. 1 , pp. $12011,2015$.

[2] M. Simic, "Design and development of air temperature and relative humidity monitoring system with AVR processor based Web server," in 2014 8th International Conference and Exposition on Electrical and Power Engineering, EPE, no. 289481, pp. 38-41, 2014.

[3] D. Palle, A. Kommu, and R. R. Kanchi, "Design and development of CC3200-based CloudIoT for measuring humidity and temperature," in 2016 Electrical, Electronics, and Optimization Techniques (ICEEOT), International Conference, pp. 3116-3120, 2016.

[4] G. V Satyanarayana, "Wireless sensor based remote monitoring system for agriculture using ZigBee and GPS," in Conference on Advances in Communication and Control Systems, pp. 110-114, 2013.

[5] R. K. Kodali and A. Sahu, "An IoT based soil moisture monitoring on Losant platform," in 2016 2 nd International Conference on Contemporary Computing and Informatics (ic3i), pp. 764-768, 2016.

[6] P. D. Vani and K. R. Rao, "Measurement and Monitoring of Soil Moisture using Cloud IoT and Android System," in Indian Journal of Science and Technology, vol. 9, no. 31, 2016.

[7] V. Boonsawat, J. Ekchamanonta, K. Bumrungkhet, and S. Kittipiyakul, "XBee wireless sensor networks for temperature monitoring," in The Second Conference on Application Research and Development (ECTI-CARD 2010), Chon Buri, Thailand, 2010.

[8] T. J. Breen, E. J. Walsh, J. Punch, A. J. Shah, and C. E. Bash, "From chip to cooling tower data center modeling: Part I influence of server inlet temperature and temperature rise across cabinet," in 2010 12th IEEE Intersociety Conference on Thermal and Thermomechanical Phenomena in Electronic Systems, ITherm, 2010.

[9] M. G. Rodriguez, L. E. O. Uriarte, Y. Jia, K. Yoshii, R. Ross, and P. H. Beckman, "Wireless sensor network for data-center environmental monitoring," in 2011 Fifth International Conference on Sensing Technology, pp. 533-537, 2011

[10] G. Fan, Y. Shen, X. Hao, Z. Yuan, and Z. Zhou, "Large-scale wireless temperature monitoring system for liquefied Petroleum gas storage tanks," in Sensors, vol. 15, no. 9, pp. 23745-23762, 2015.

[11] D. Dobrilović, Ž. Stojanov, Z. Čović, J. Simon and N. Petrov, "Model of data center temperature monitoring system with the use of open source hardware," in 2016 IEEE 14th International Symposium on Intelligent Systems and Informatics (SISY), Subotica, pp. 221-226, 2016.

[12] A. H. Ali, A. H. Duhis, N. Aad, L. Alzurfi, and M. J. Mnati, "Smart monitoring system for pressure regulator based on IOT," in International Journal of Electrical and Computing Engineering (IJECE), vol. 9, no. 5, pp. 3450-3456, 2019. 
[13] A. A. Jaber, F. K. I. Al-Mousawi, and H. S. Jasem, "Internet of things based industrial environment monitoring and control: a design approach,"in International Journal of Electrical and Computing Engineering (IJECE), vol. 9, no. 6, pp. 4657-4667, 2019.

[14] S. Sankar, M. Shaw, K. Vaid, and S. Gurumurthi, "Datacenter Scale Evaluation of the impact of temperature on hard disk drive failures," in ACM Transactions on Storage (TOS), vol. 9, no. 2, pp. 6:1-6:24, 2013.

[15] J. Chen, R. Tan, Y. Wang, G. Xing, X. Wang, X. Wang, B. Punch, and D. Colbry, "A high-fidelity temperature distribution forecasting system for data centers," in Proceedings-Real-Time Systems Symposium, pp. 215-224, 2012.

[16] J. Niemann, K. Brown, and V. Avelar, "Impact of hot and cold aisle containment on data center temperature and efficiency," APC White Paper, Revisi, vol. 135, 2011.

[17] A. J. Samuel, S. Sebastian, and A. J. Samuel, "An algorithm for IoT based vehicle verification system using RFID corresponding author," in International Journal of Electrical and Computing Engineering (IJECE), vol. 9, no. 5, pp. 3751-3758, 2019.

[18] S. Sharma and S. Sebastian, "IoT based car accident detection and notification algorithm for general road accidents," in International Journal of Electrical and Computing Engineering (IJECE), vol. 9, no. 5, pp. 4020-4026, 2019.

[19] F. Hashim and R. Mohamad, "Implementation of Embedded Real-Time monitoring temperature and humidity system," in Indonesian Journal of Electrical Engineering and Computer Science (IJEECS), vol. 16, no. 1, pp. 3-6, 2019.

[20] M. Zdravkovi, M. Trajanovi, M. Lezoche, A. Aubry, R. Jardim-gon, M. Zdravkovi, M. Trajanović, J. Sarraipa, R. Jardim-gonçalves, and M. Lezoche, "Survey of Internet-of-Things platforms," in 6th International Conference on Information Society and Technology, ICIST 2016, pp. 216-220, Feb 2016.

[21] J. Mineraud, O. Mazhelis, X. Su, and S. Tarkoma, "Contemporary Internet of Things platforms," in arXiv preprint arXiv:1501.07438., pp. 1-6, 2015.

[22] E. N. Power, "Precision versus comfort cooling choosing a cooling system to support business-critical IT environments," USA, 2010

[23] N. Rasmussen, "Avoidable mistakes that compromise cooling performance in data centers and network rooms," 2003.

[24] A. Beldjazia and D. Alatou, "Precipitation variability on the massif forest of Mahouna (North Eastern-Algeria) from 1986 to 2010," in International Journal of Management Sciences and Business Research ISSN, vol. 5, no. 3, pp. 2226-8235, 2016.

[25] N. M. S. Hassan, M. M. K. Khan, and M. G. Rasul, "Temperature monitoring and CFD analysis of data centre," Procedia Engineering, vol. 56, pp. 551-559, 2013.

[26] P. Lin, S. Zhang, and J. VanGilde, "Data center temperature rise during a cooling system outage," 2014.

[27] S. Bhopte, D. Agonafer, R. Schmidt, and B. Sammakia, "Optimization of data center room layout to minimize rack inlet air temperature," in Journal of Electronic Packaging, vol. 128, no. 4, pp. 380-387, 2006. 